\title{
Experimental Investigation of Drag Reduction with polymer of Kerosene flow in a horizontal pipe
}

\author{
Adil Abbas Alwan and Ali Jassim Mohammad* \\ Department of Mechanical Engineering University of Babylon, Iraq \\ Received 15 Jan 2018, Accepted 20 March 2018, Available online 25 March 2018, Vol.8, No.1 (March 2018)
}

\begin{abstract}
flow, where adding certain amount of drag reducing agent, such as polymer. From addition of that agent, it causes a dramatic frictional drag reduction. This work shows the effect of the pressure drop on a drag reduction along pipe in a horizontal placing with kerosene flow is investigated. The tested fluid was kerosene and poly isobutylene polymer (PIB) with $50 \mathrm{ppm}$ (part per million), 75 ppm, and 100 ppm weight concentration of polymer: Experimental investigation gives more description of this phenomenon. The experimental results illustrate that pressure drop and pressure gradient decreases with increasing of polymer concentration and volume flow rate. The friction factor decreases with increasing of additive concentration and velocity. The drag reduction percentage increases with increasing the mean velocity, polymer concentration and temperature. The experimental results show that maximum drag reduction (DR \%) about $19 \%$
\end{abstract}

Keywords: Kerosene flows, polymer, pressure drop, drag reduction

\section{Introduction}

Drag reduction can be defined as a phenomenon of flow in which very little quantity of a certain additive, for instance, little concentration of additive per million of the fluid can give significant reduce of friction factor for turbulent fluid flow. The objective of drag reducing percentage is to develop the efficiency of fluid mechanical by using active additives which are known as a drag reduction agent. The percentage of drag reduction (DR \%) can be defined as the ratio of frictional pressure drop difference between adding and non-adding of additive to the pressure drop at nonadding with the same flow rate multiplied by 100 . (Sher and Hetsroni, 2008) showed that by adding few concentrations of polymer with high molecular weight to the solvent of (gas oil) or other fluid can be produce high reduction in pressure drop of friction in turbulent flow, leads to possible of increasing capacities of pipelines and ships becomes faster. They explain that the high length fibers ratio to width is long cylinder like objects. They orientated themselves to the drag reducing direction of flow to state that fiber suspending occurs in a widely variety of inbred or materials in man-made. The microstructure investigation of fibers has been received attention about the properties of electrical, mechanical, and thermal. For composite fiber are highly sensitive for

*Corresponding author: Ali Jassim Mohammad DOI: https://doi.org/10.14741/ijtt/v.8.1.4 distribution and configuration of fiber. Such has complicated physical properties suspending different from in the suspending fluid, albeit for low concentrations.

(Zadearzal and Markides, 2014) obtained experimentally from the Particle Image Velocimetry PIV measurements on that the scales of the drag reduction with the quantum of the normalized stream wise and span wise ( rms) velocity fluctuations in the flow, it was measured in pressure driven flow facility in horizontal pipe with diameter $25.3 \mathrm{~mm}$ and Reynolds number from 3500 to 210000 , and the concentration of the linear non-ionic water soluble polymer polyethylene oxide (PEO) was $(5,10,25,50,75,125$ and 250 w. ppm, were the molecular weight $2 \times 10^{6} 4 \times 10^{6}$ $8 \times 10^{6} \mathrm{~g} / \mathrm{mol}$, This is as a results, and the scaling seems to universal, independent of the Reynolds number, also in some cases if the velocity fluctuations considered it is independent of the distance from the wall, the drag reduction indicated increases by the observations of the instantaneous Particle Image Velocimetry, the flow separated into a high momentum flow region in the core of the pipe and low momentum flow region near the pipe wall. They investigated that by using nonintrusive laser and based on diagnostic technique PIV, where measured experimentally the drag reduction in turbulent pipe flow with polymer additives during over 122 experimental conditions with varying polymer molecular weight, concentration, and different Reynolds number, where the maximum level of drag reduction was observed $72 \%$. 
(Khadom and Abdul-Hadi, 2014) reported that the influence of polyacrylamide (PAM) as drag reducing polymer on flow of Iraqi crude oil in pipe lines was investigated in the present work. The effect additive concentration, pipe diameter, solution flow rate and the presences of radius elbows on the percentage drag reduction (DR \%) and the amount of flow increases (FI $\%)$ were the variables of study. Maximum drag reduction was $40.64 \%$ which was obtained with 50 ppm of PAM polymer flowing in straight pipes of $0.0508 \mathrm{~m}$ I.D. the dimensional analysis was used for grouping the significant quantities into dimensionless group to reduce the number of variables. The results showed good agreement between the observed drag reduction percent values and the predicted ones with high value of correlation coefficient.

(Shahath, 2015) showed experimentally and theoretically that there is percentage drag reduction increasing due to increasing in the additives percentage increase until the drag reduction reaches to the maximum value this value occurs at saturation concentration, where this concentration was called critical value and after these saturation values the drag reduction beginning in the decreases. And in the other side the drag reduction increased with increasing the Reynolds number also until reaches maximum value where Reynolds number becomes 66836 and then starts to decrease when it exceeds this value of Reynolds number, and reported that the drag reduction for mixing of polymers and surfactants with salt more than for each of polymer and surfactants.

In the present work experimental work was designed to measure the temperature, pressure, and the velocity flow through the length of circular pipe. Drag reduction with and without polymer additives for kerosene for single-phase flow. It was focused the effect of temperature on the drag reduction through working time.

\section{Experimental work}

\subsection{Working Fluid}

The kerosene liquid was the main fluid that used in this experimental with density $\left(770 \mathrm{~kg} / \mathrm{m}^{3}\right)$, specific heat capacity $\left(2010 \mathrm{~J} / \mathrm{kg} .{ }^{\circ} \mathrm{C}\right)$, flash point $\left(59^{\circ} \mathrm{C}\right)$, dynamic viscosity $0.0019 \mathrm{~kg} / \mathrm{m} . \mathrm{s}$ at $20^{\circ} \mathrm{C}$.This working fluid were mixed with linear polymer of high molecular weight more than 『10】_^ $6 \mathrm{~g} / \mathrm{mol}$.

\subsection{Drag reduction agent}

Poly isobutylene (PIB) was used with different concentrations $(50,75$, and100) ppm with density $(915$ $\mathrm{Kg} / \mathrm{m}^{3}$ ), and high molecular weight, high ability soluble in kerosene with low affectivity on kerosene chemical property.

\subsection{Description of Flow System}

The schematic diagram of the experimental rig was illustrated in figure 1 . The test section consists of a pipe has $80 \mathrm{~mm}$ inside diameter and $6 \mathrm{~m}$ length (where $4 \mathrm{~m}$ length made of carbon steel with $2 \mathrm{~mm}$ thickness, and $2 \mathrm{~m}$ length of Pyrex glass pipe). The two pipes were connected to each other by two flanges with rubber to reduce structural vibrations transmitter. The test pipe was divided into five sections, four of carbon steel with $1 \mathrm{~m}$ length, and one section of Pyrex glass pipe with $2 \mathrm{~m}$ length. Also, the experimental rig consists of a fluid reservoir, electric motor, gear pump, control valve, liquid flow meter, pressure sensors, thermocouples, stand, and drain.

\subsection{Experimental Procedure}

The mixing way of the polymer with the kerosene that was by using gradation flask with scales in $(\mathrm{ml})$ where a certain volumes of poly isobutylene (PIB), (12.5, 18.75 , and $25 \mathrm{ml}$ ). Then, it was solved in the flask with a certain volume of kerosene and it is jiggles and it is take time 2 hours to become viscous liquid. Then, it was mixed in the reservoir with the kerosene. The working fluid was used to circulate through a pipe in semi-closed system. The operation system begins where working fluid pumping through a test pipe sections with constant diameter, a numbers of additive concentrations $(50,75$, and 100$)$ ppm with a number of runs for a certain volume flow rates, were reading pressure drop for each runs due to changing the volume flow rate and additive concentration. These procedures were repeated foe each concentration and volume flow rate in order to get true result. The pressure was measured at all sections of pipe by the pressure sensors. Then, these were connected with interface system and personal computer. The pressure sensor reading was calibrated by using electrical manometer. Velocity was measured for five sections by using Ultrasonic flow meter. This was calibrated by using liquid flow meter. Through these measurements the temperature of working fluid was recorded in the five sections, and the wall of pipe by using temperature recorder device which was used thermocouple type $\mathrm{K}$. these readings of temperature were calibrated by using a laser infrared thermometer.

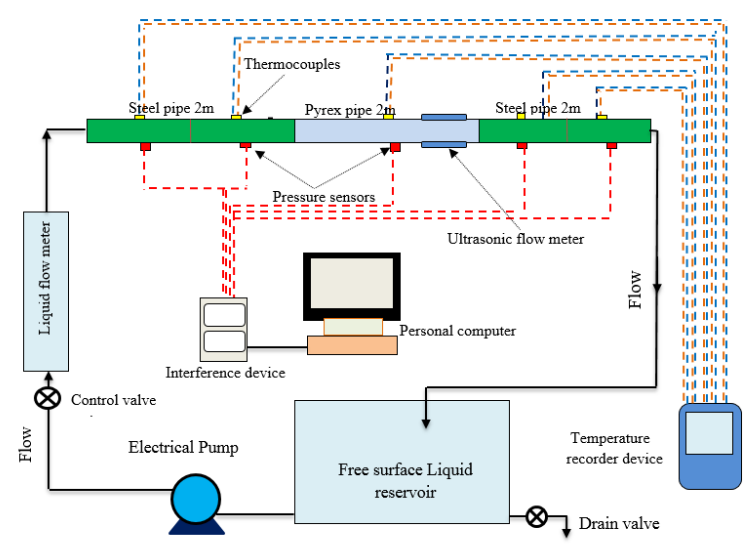

Figure 1 Schematic diagram of the experimental rig 


\section{Results and Discussion}

\subsection{Results Calculations}

The number of operations for experimental runs was more than 150 to measure the pressure velocity, and temperature through different working time. The equations were used in these experimental calculations which were reported by (Holland and Bragg, 1995) to calculate pressure drop along the pipe sections, Reynolds number Re, the drag reduction percentage DR\%, shear stress $(\tau)$, friction factor $(f)$ respectively.

$$
\begin{aligned}
& R e=\frac{\rho u D}{\mu} \\
& \tau=\left(\frac{\Delta P}{\Delta z}\right)\left(\frac{D}{4}\right) \\
& f=\frac{\tau}{\frac{1}{2} \rho u^{2}} \\
& D R \%=\left(\frac{\Delta p_{N}-\Delta p_{a}}{\Delta p_{N}}\right)=\left(\frac{f_{N}-f_{a}}{f_{N}}\right)
\end{aligned}
$$

Where $u$ is mean velocity, $\rho$ is density, $\mu$ is viscosity, $D$ is pipe diameter, $(\Delta \mathrm{p}) \_\mathrm{N}$ is pressure drop with no polymer additive, $(\Delta \mathrm{p}) \_\mathrm{a}$ is pressure drop with polymer additive, $\Delta \mathrm{z}$ is distance of the pressure drop on the pipe. Table 1 shows the calculation values of pressure drop through the pipe with different values of polymer concentration. It was indicated that the pressure drop decreasing with increasing the percentage of polymer concentration. Also, it was appears that the pressure drop increasing with increasing the values of flow velocity of working fluid through the pipe. While table 2 observes the estimation of shear stress with different polymer concentrations, it was pointed that the shears stress decreasing with increasing the polymer concentrations. Table 3 represents the friction factor calculation according to the shear stress for different velocity with different of polymer concentration. This table shows that friction factor decreasing with flow velocity of working fluid increasing and with polymer concentrations increasing. Table 4 illustrates the values of drag reduction percentage with different polymer concentrations and different flow velocity of working fluid. From this table noted that the drag reduction percentage increasing with polymer concentration increasing and with flow velocity increasing.

\subsection{Effect of Polymer concentration}

Figure (2) represents the relation between the pressure drops with flow velocity for different polymer concentration. This figure shows that the pressure drop increases with flow velocity increasing. High increasing value was pointed after the value of velocity $1.74 \mathrm{~m} / \mathrm{s}$. The pressure drop was proportional inversely with polymer concentration of working fluid. The pressure drops decreases with polymer concentration increasing. These results were consistent with experimental results of (Abid, 2007).
Table 1 Experimental data of pressure drop with different polymer concentration for different velocity

\begin{tabular}{|c|c|c|c|c|}
\hline Velocity m/s & $\begin{array}{c}\boldsymbol{\tau} / \text { Con } \\
=0 \mathrm{ppm}\end{array}$ & $\begin{array}{c}\boldsymbol{\tau} / \text { Con } \\
=50 \mathrm{ppm}\end{array}$ & $\begin{array}{c}\boldsymbol{\tau} / \text { Con } \\
=75 \mathrm{ppm}\end{array}$ & $\begin{array}{c}\boldsymbol{\tau} / \text { Con }=100 \\
\mathbf{p p m}\end{array}$ \\
\hline 0.87 & 0.0404 & 0.0388 & 0.0368 & 0.034 \\
\hline 1.55 & 0.046 & 0.044 & 0.0416 & 0.0388 \\
\hline 1.77 & 0.05 & 0.0472 & 0.0456 & 0.042 \\
\hline 1.9 & 0.0592 & 0.0568 & 0.054 & 0.051 \\
\hline
\end{tabular}

Table 2 Experimental calculation of shear stress with different polymer concentration for different velocity

\begin{tabular}{|c|c|c|c|c|}
\hline Velocity m/s & $\begin{array}{c}\boldsymbol{\tau} / \text { Con } \\
=0 \mathrm{ppm}\end{array}$ & $\begin{array}{c}\boldsymbol{\tau} / \text { Con } \\
=50 \mathrm{ppm}\end{array}$ & $\begin{array}{c}\boldsymbol{\tau} / \text { Con } \\
=75 \mathrm{ppm}\end{array}$ & $\begin{array}{c}\boldsymbol{\tau} / \text { Con }=100 \\
\mathrm{ppm}\end{array}$ \\
\hline 0.87 & 10.1 & 9.7 & 9.2 & 8.5 \\
\hline 1.55 & 11.5 & 11.1 & 10.5 & 9.7 \\
\hline 1.77 & 12.3 & 11.7 & 11.3 & 10.3 \\
\hline 1.9 & 14.8 & 14.2 & 13.6 & 12.8 \\
\hline
\end{tabular}

Table 3 eExperimental calculation of friction factor with different polymer concentration for different velocity

\begin{tabular}{|c|c|c|c|c|}
\hline Velocity m/s & $\begin{array}{c}\boldsymbol{f} / \text { Con }=0 \\
\mathrm{ppm}\end{array}$ & $\begin{array}{c}\boldsymbol{f} / \text { Con } \\
=50 \mathrm{ppm}\end{array}$ & $\begin{array}{c}\boldsymbol{f} / \text { Con } \\
=75 \mathrm{ppm}\end{array}$ & $\begin{array}{c}\boldsymbol{f} / \text { Con } \\
=100 \mathrm{p} \mathrm{pm}\end{array}$ \\
\hline 0.87 & 0.000138 & 0.000132 & 0.000125 & 0.000115 \\
\hline 1.55 & 0.000049 & 0.000047 & 0.0000449 & 0.0000414 \\
\hline 1.77 & 0.0000407 & 0.0000385 & 0.000037 & 0.000033 \\
\hline 1.9 & 0.00004 & 0.000038 & 0.000035 & 0.000034 \\
\hline
\end{tabular}

Table 4 Experimental calculation of drag reduction with different polymer concentration, different velocity

\begin{tabular}{|c|c|c|c|}
\hline Velocity m/s & $\begin{array}{c}\mathrm{DR} \% \\
\mathrm{Con}=50 \\
\mathrm{ppm}\end{array}$ & $\begin{array}{c}\mathrm{DR} \% \\
\mathrm{Con}=75 \\
\mathrm{ppm}\end{array}$ & $\begin{array}{c}\mathrm{DR} \% \\
\mathrm{Con}=100 \\
\mathrm{ppm}\end{array}$ \\
\hline 0.87 & 6.2 & 9.7 & 15 \\
\hline 1.55 & 7.2 & 12.6 & 18.5 \\
\hline 1.77 & 8.2 & 14.2 & 18.8 \\
\hline 1.9 & 8.5 & 14.5 & 19 \\
\hline
\end{tabular}

Figure (3) reveals the effect of velocity on wall shear stress for different polymer concentrations in pipe for inside diameter $80 \mathrm{~mm}$ and $6 \mathrm{~m}$ long test section. It was noted that the wall shear stress increases with increasing the flow velocity. However by increasing the polymer concentration the shear stress decreases until reach minimum value at concentration equal $100 \mathrm{ppm}$. The wall shear stress increases with the velocity until reach maximum value $0.0592 \mathrm{kpa}$ at velocity $1.9 \mathrm{~m} / \mathrm{s}$ for flow of pure kerosene at average temperature 47 $o C$. At the same concentration for working fluid, the shear stress drops until value $0.0512 \mathrm{kpa}$ at the same velocity $1.9 \mathrm{~m} / \mathrm{s}$. This experimental result was confirmed by experimental result of (Abid, 2007).

Figure (4) demonstrates the determination of the friction factor depending upon the values of shear stress It is shown that the friction factor decreases with increasing the velocity, and decreases with increasing 
additive polymer concentration This result agrees with experimental result of (Campolo et al., 2013).

Figure (5) shows that the effect of concentration of polymer on the drag reduction percentage, and can be calculated with different volume flow rate. This figure shows that the percentage of drag reduction increases with increasing the polymer concentrations for different value of volume flow rate at working time of 90 minutes. It was described that the drag reduction increases from $6.2 \%$ to $15 \%$ for polymer concentration increasing from 50 to $100 \mathrm{ppm}$ at volume flow rate 200 $1 / \mathrm{min}$. These results were valid with the experimental results of (Shahath, 2015).

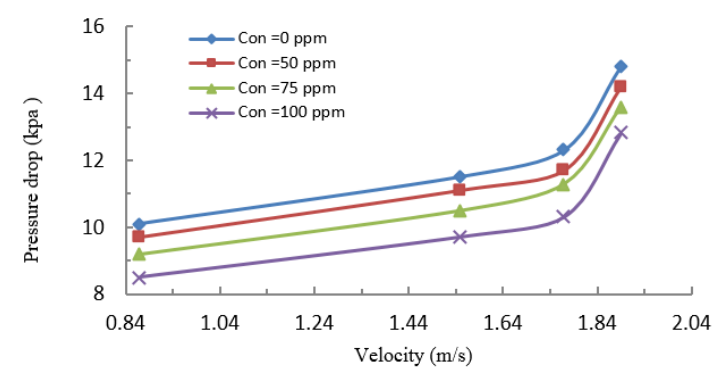

Figure 2 Pressure drop with velocity for different polymer concentration at temperature $45^{\circ} \mathrm{C}$

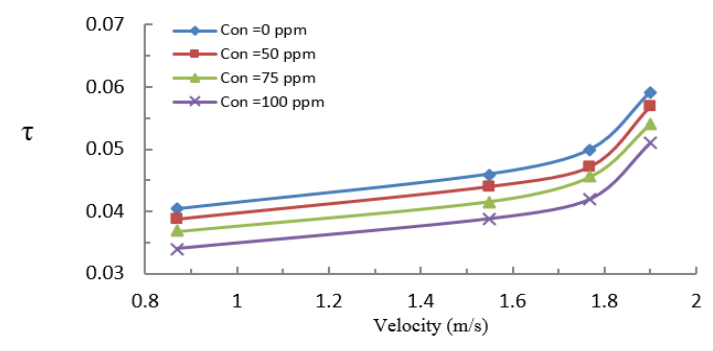

Figure 3 Shear stress with velocity for different polymer concentration at temperature $45^{\circ} \mathrm{C}$

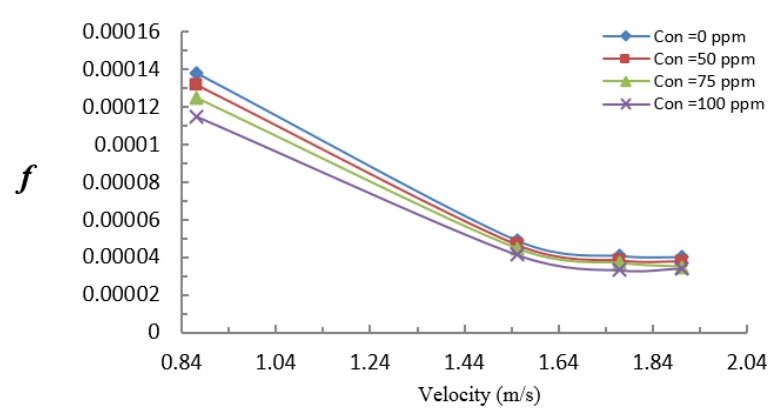

Figure 4 Friction factor with velocity for different polymer concentration at temperature $45^{\circ} \mathrm{C}$

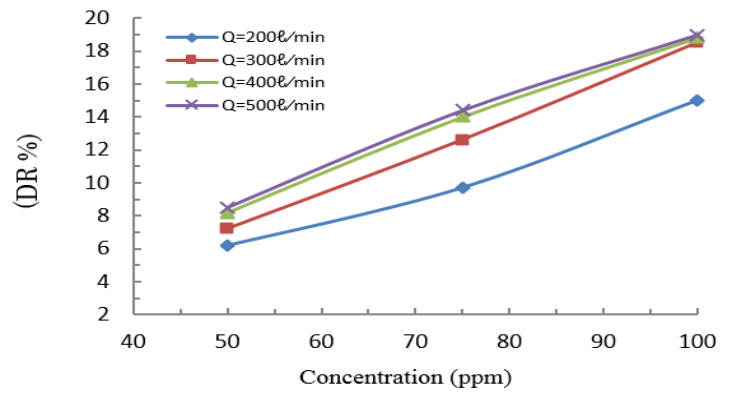

Figure 5 Drag reduction with polymer concentration for different volume flow rate, at temperature $45^{\circ} \mathrm{C}$

\subsection{Effect of Flow Velocity}

Figures (6-8) illustrate the effect of flow velocity on drag reduction with different temperature, from these figures noted that the drag reduction percentage increases with flow velocity increasing, and with temperature increasing. Maximum drag reduction was $19 \%$ such as shown in figure (8). These results are confirmed with the experimental results of (Abid Ali and Al-ausi ,2008).

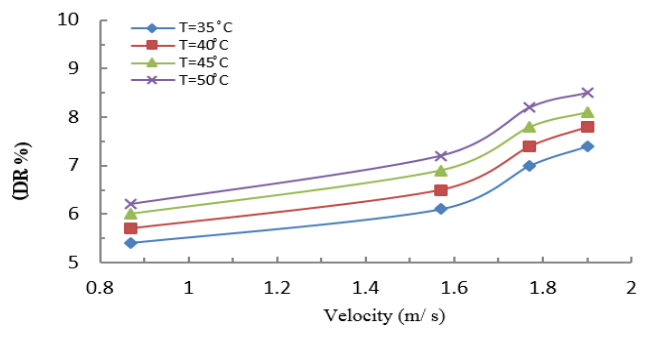

Figure 6 Effect of velocity on drag reduction percentage for different temperature at polymer $\mathrm{C}=50 \mathrm{ppm}$

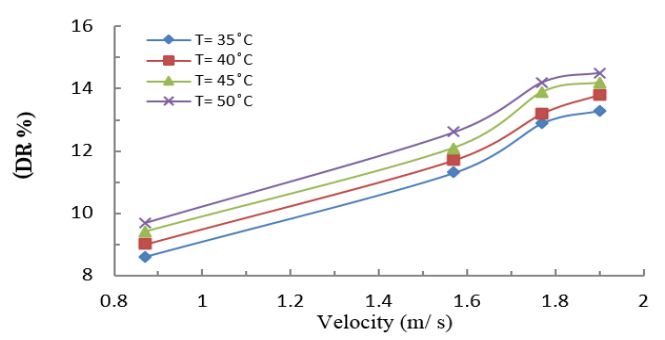

Figure 7 Effect of velocity on drag reduction percentage for different temperature at polymer $\mathrm{C}=$

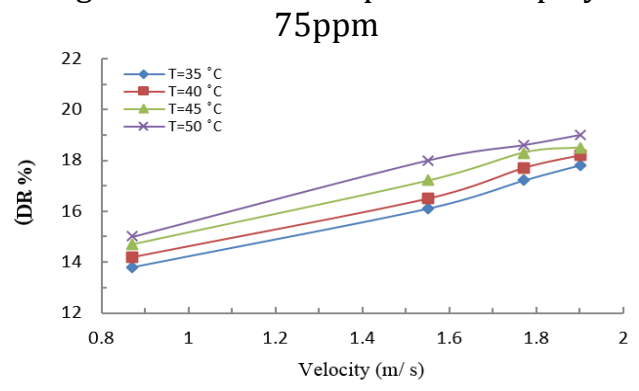

Figure 8 Effect of velocity on drag reduction percentage for different temperature at polymer $\mathrm{C}=$ $100 \mathrm{ppm}$ 


\section{Conclusions}

1) The polymer poly isobutylene PIB wa suitable type of polymer can be used as a drag reduction additive with kerosene in turbulent pipe flow without effect on the properties of the kerosene as an energy fluid.

2) Through the experimental work, it was measured the temperature for pure working fluid (kerosene), and working fluid with different percentage of polymer additive through working time. It was found that the time of working fluid to reach its flash point was decreased with increasing the polymer concentration.

3) The pressure drop was increased with increasing the velocity, and decreased with increasing the polymer concentration.

4) The shear stress and friction factor were calculated from the experimental data of pressure. It was explained that the shear stress was increased with velocity increasing, and decreased with increasing of polymer concentration, while friction factor was decreased with increasing velocity and polymer concentration.

5) The drag reduction percentage (DR \%) was calculated from the experimental data of pressure drop through the length of pipe. It was found this percentage increasing with increasing the working velocity, and polymer concentration. Also, it was pointed that the drag reduction was increased with increasing of temperature values through the time of working

\section{References}

Sher, I., and Hetsroni, G., 2008, A mechanistic Model of Turbulent drag Reduction by Additives, J. of chemical Engineering Sciences, vol. 63, pp. 1771- 1778,.

Zadearzal , F. , and Markides, C.W., 2014, A Mechanism of Polymer Induced Drag Reduction in Turbulent Pipe Flow, 10 th International Conference on Heat Transfer, Fluid Mechanics and Thermodynamics, Oriando, Florida, USA, 14-16 July.

Khadom, A. A. , and Abdul-Hadi, A. A. , 2014, Performance of Polyacrylamide as drag Reduction Polymer of Crude Petroleum Flow, Ain Shams Engineering Journal, Vol. 5, pp. 861-865

Shatath, A. A., 2015, Drag Reduction in Turbulent Pipe Flow Using Additives, M.Sc. Thsis, Department of Mechanical Engineering, University of Babylon.

Holland , F. A, and Dragg R., 1995, Fluid Flow for chemical engineers, Book, 2nd .ed. U.K, Edward Arnold.

Abid , E. M. , 2007, Drag Reduction in Single and Tow-Phase Turbulent Pipe Flow Using CMC Polymer, Ph. D. Thesis, Mechanical Engineering, University of Technology, March.

Campolo , M. ,Simeonti,M., Lapusin, R., and Soldati A., 2013, Drag Reduction by bio-polymer additives in industrial size turbulent flow, Studio University, C.I.F.I. , 6th Joint MC/WG Meeting - Udine, October 23th

Abid Ali , Q. M., and Al-ausi, T. A., 2008, Drag Force Reduction of Flowing Crude Oil by Polymer Addition, Iraq Journal For Mechanical and Natural Engineering, Vol. 8, No. 2, pp. 149161 . 